\title{
Aloe vera
}

\author{
Paula Marques Borges
}

Instituto de Química, Universidade Federal da Bahia, Campus de Ondina, Salvador - BA - Brasil, CEP 40170-290 (amadinhaporto@???)

\section{Objetivo}

Este trabalho visa analisar o grau de desenvolvimento tecnológico e potenciais utilzações da Aloe vera.

\section{Aspectos tecnológicos}

A Aloe vera ( A. barbadensis Mill., A. vulgaris Lam.), vulgo babosa, teve origem na África meridional.

O nome Aloe vera vem do hebráico halal ou do arábico alloeh que significa substância amarga, brilhante e do latim vera, verdadeira. Para os egípcios, a planta é atribuída à rainha Cleópatra, signo de beleza.

Alexandre Magno, nas Ilhas de Socotorá no Oceano Índico (século IV a.C.), usou-a como paliativo para os ferimentos de guerra.
Nos Estados Unidos, em 1994, foi estudada no combate de Aids e de câncer.

Há mais de 250 espécies conhecidas da planta. Alguns benefícios da planta, que é considerada curadora, são: inibidora da dor, antiflamatória, regeneradora celular, antibiótico, digestivo, energético e nutritivo, ativa a circulação sanguínea.

A planta contém: aloesone, aloesin, isoaloesin, ácido tartárico e cítrico das folhas; aminoácidos, minerais, vitaminas e enzimas.

\section{Escopo}

Pesquisa realizada em outubro de 2007, na base de dados Espacenet, sendo analisadas 187 patentes com as palavras-chave aloe* e treat*.

Tabela de pesquisa por palavras-chave e código de classificação internacional

\begin{tabular}{|c|c|}
\hline Palavras-chave e códigos & Espacenet \\
\hline aloe* medic* & 116 \\
\hline aloe* vera* & 211 \\
\hline aloe* cosmetic* & 99 \\
\hline aloe $^{*}$ cosmetic ${ }^{*}$ and $\mathrm{A} 61 \mathrm{~K} 7 / 00$ & 26 \\
\hline aloe* treat* & 187 \\
\hline aloe* health* & 170 \\
\hline aloe* medic* health* & 49 \\
\hline aloe* and $\mathrm{A} 61 \mathrm{~K}$ & 538 \\
\hline aloe* and $\mathrm{A} 61 \mathrm{~K} 7 / 00$ & 26 \\
\hline aloe* and $\mathrm{A} 61$ & 546 \\
\hline aloe* health* and A61 & 58 \\
\hline
\end{tabular}




\section{Resultados e Discussão}

1. Evolução Anual de Depósitos de Patentes

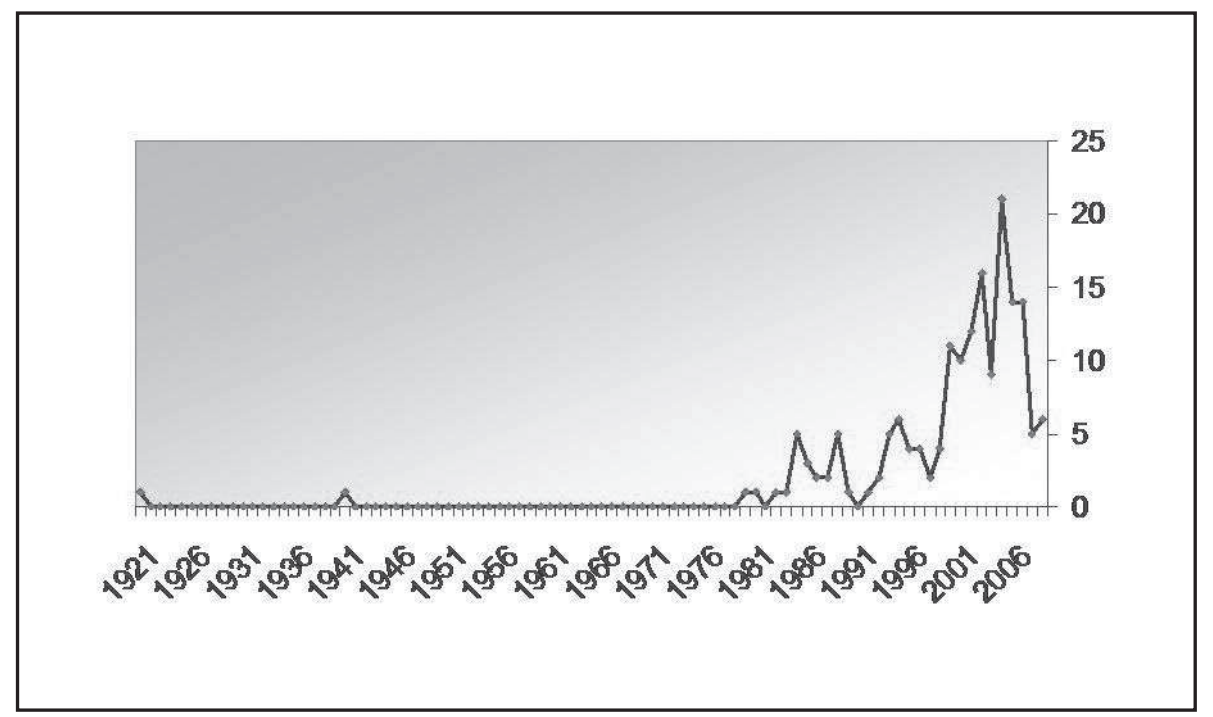

\section{Patentes por Empresa}

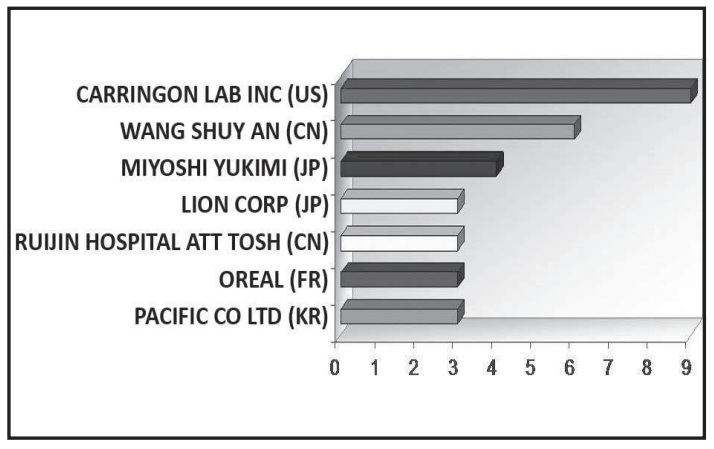

3. Distribuição por Código de Classificação Internacional

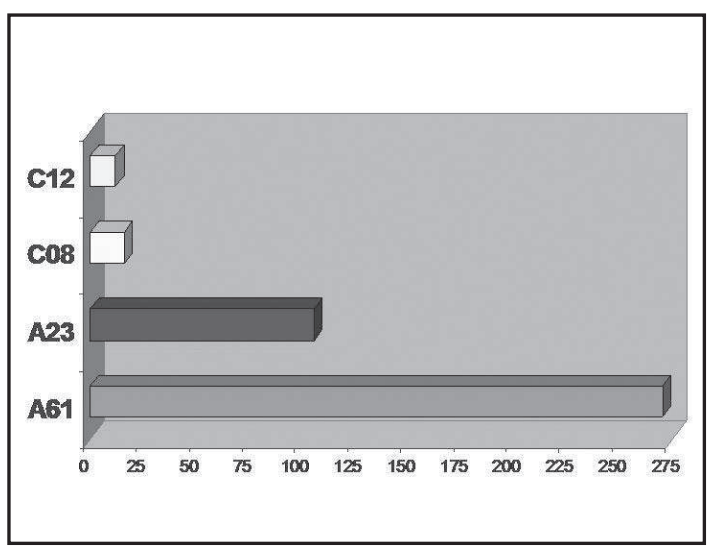

C12- Vinho;

C08- Polissacarídeos e seus derivados;

A23- Alimento ou produtos alimentícios;

A61- Ciência médica ou veterinária, higiene.
Alimentos ou produtos alimentícios

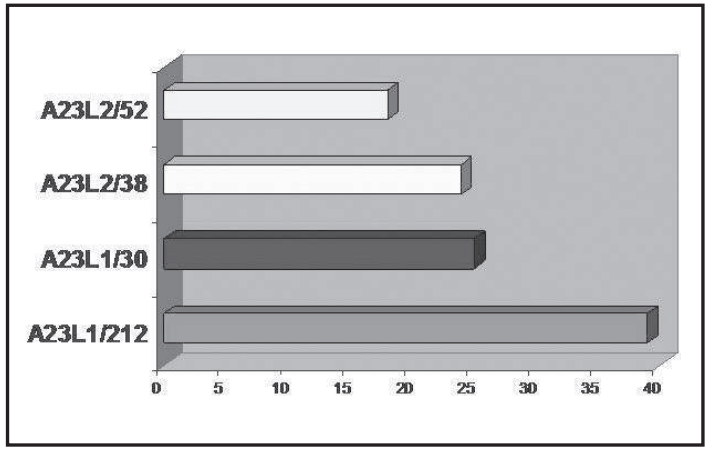

A23L2/52- Acrescentando ingredientes;

A23L2/38- Bebidas não alcoólicas;

A23L1/30- Contendo aditivos;

A23L1/212- Preparo de frutas ou legumes.

Ciência médica ou veterinária, higiene

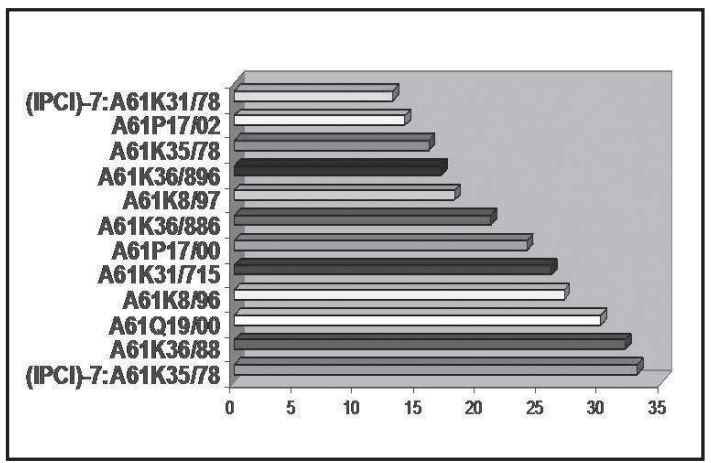

A61K31/78- Ácido acrílico e seus derivados;

A61P17/02- Tratamento de feridas, queimaduras; A61P17/00- Drogas para tratamento dermatológico; A61K31/715- Polissacarídeos;

A61K35/78- Materiais derivados de plantas. 
4. Patentes por Principais Inventores

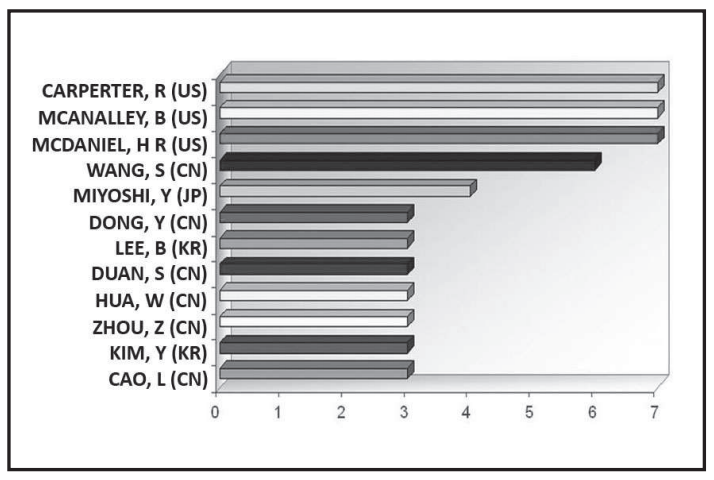

A ISAC é uma organização sem fins lucrativos em prol da indústria mundial da Aloe vera que possui sede no Texas, cujos membros são cultivadores, processadores, manufatureiros, empresas comercializadoras, fornecedores de equipamentos, físicos, cientistas e pesquisadores.

\section{Principais Usos das Patentes}

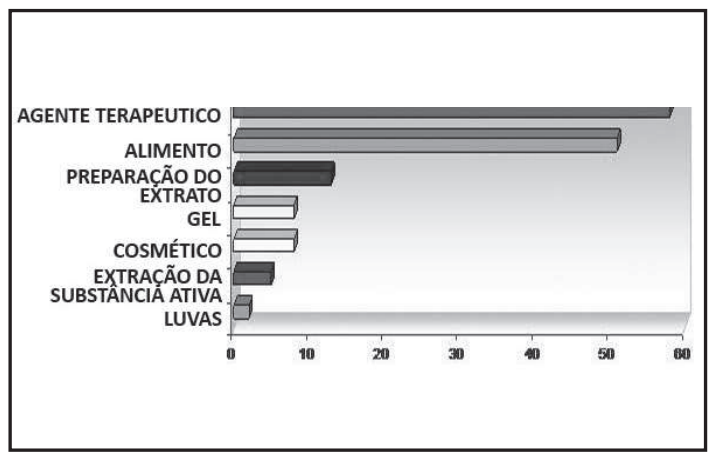

Alimentos ou produtos alimentícios

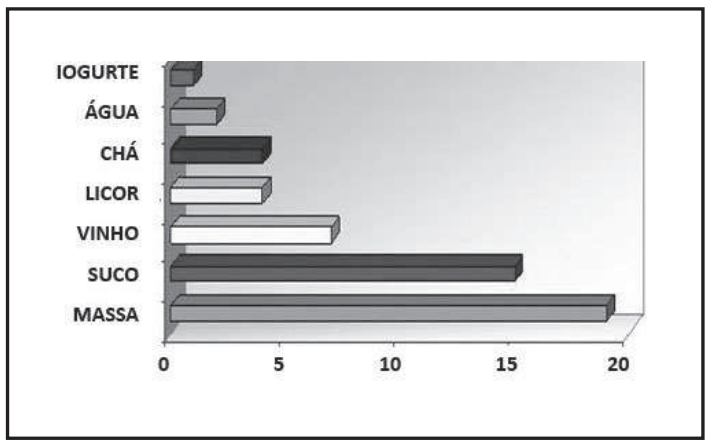

Ciência médica ou veterinária, higiene

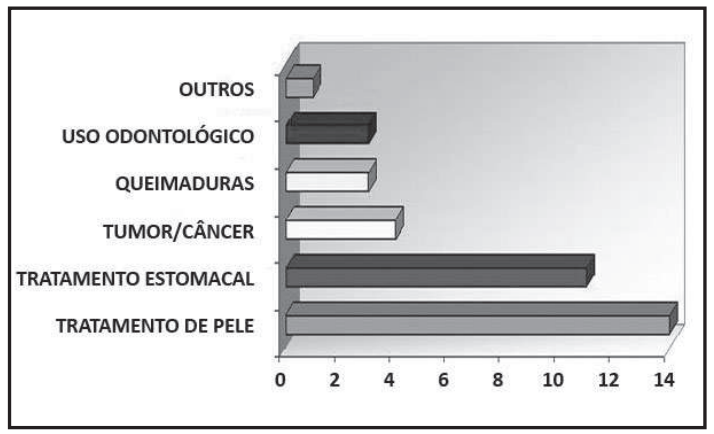

Segundo Michael Peuser (um dos maiores pesquisadores no mundo sobre o grande poder medicinal da planta): "Se houvesse uma farmácia que oferecesse todos os remédios fabricados no mundo, $25 \%$ de suas substâncias ativas também se encontrariam na Aloe". Foram-lhe concedidas patentes em mais de 30 países.

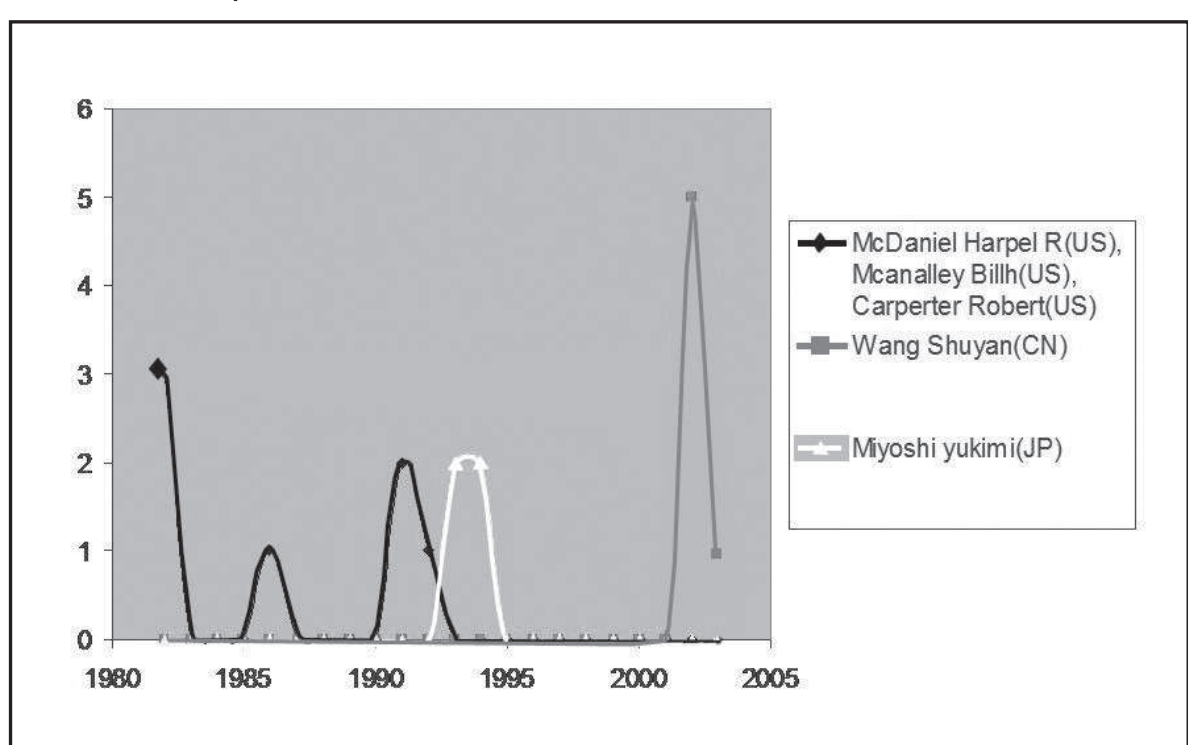




\section{Patentes por País/Organização}

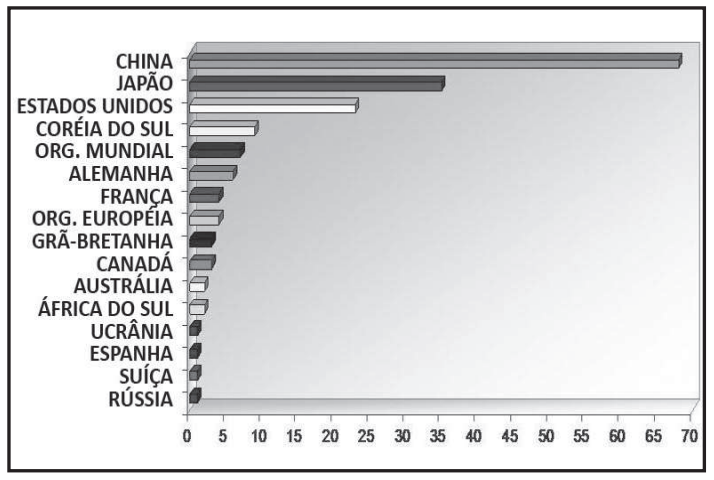

Somente depois dos bombardeios atômicos das cidades japonesas de Hiroshima e Nagasaki (1945), que causaram terríveis queimaduras, a Aloe foi arrancada, internacionalmente, de seu esquecimento, por se revelar um excelente remédio para esses males. Pode ser atribuído a esse fato o Japão ser o segundo país mais sgnificativo no depósito de patentes relacionadas à planta, seguindo a China.

\section{Conclusões}

As pesquisas sobre a babosa são antigas, mas teve um grande crescimento recentemente, mais ou menos em 1993.

Foram depositadas mais patentes na China e no Japão.

Os pesquisadores dos EUA publicam mais dentre todos os outros, embora existam mais pesquisadores de Aloe na China.

As empresas dos EUA são as que depositam mais patentes, mas é maior o número de empresas na China que fazem depósito de patentes.

Os pesquisadores dos EUA iniciaram os estudos sobre aloe, mas atualmente a China lidera este campo de pesquisa.

As pesquisas por tema e código demonstram que existem mais estudos relacionadas com os segmentos alimentícios e terapêuticos, e que as pesquisas relacionadas com cosméticos e o gel da babosa possuem ainda um campo vasto para pesquisa.

Os estudos relacionados com o poder curativo da planta tiveram um crescimento significativo após a Conferência das Nações Unidas para o Meio Ambiente e o
Desenvolvimento, da qual resultou o convênio sobre diversidade biológica.

De acordo com o gráfico "Número de patentes depositadas por país", podemos inferir que a China e o Japão, por possuírem uma cultura de uso de ervas medicinal, destacam-se com um excelente mercado consumidor da Aloe. Existem mais incentivos para pesquisadores e aplicantes nos EUA, pois existem organizações em prol Indústria mundial da Aloe Vera com sede neste país.

Existe ainda muito a ser investigado sobre o Aloe. Linhas de pesquisa que podem trazer grandes benefícios para toda a sociedade, como por exemplo a cura de cânceres e tumores, ainda contam com poucos estudos em comparação com as demais.

Devido ao seu potencial em diversas áreas de aplicação, e ao crescente número de estudos referentes ao aloe, é provável que o seu consumo e comercialização cresçam cada vez mais. Segundo alguns cientistas (Dr. Reginald Mc Daniel, Dr. Faith Strickland e Dr. Michael Peuser), no futuro esta planta milenar se tornará a mais importante ferramenta contra o câncer.

\section{Referências}

A.Ikuro, W. Tatsuya, L. Weiwer, N. Hiroshi, Active site residues governing substrate selectivity and polyketi de chain lenght in aloesone synthase, The FEBS Journal 273, ano 2006, pág. 209 w w w. es a l q. us p.br/sies a l q / p m / cultivo_babosa.pdf, acessado em 17 de novembro de 2007 ás 10 h.

Paula Marques Borges é aluna de graduação em Química da UFBA. Este trabalho foi realizado no semestre de 2007.2 durante a disciplina optativa "Marcas, Patentes e Propriedade Industrial" ministrada pela Prof $^{a}$. Cristina M. Quintella. Não tinha tido contato anterior com o tema. 